Article

\title{
Application of Multiple Unipolar Axial Eddy Current Brakes for Lightweight Electric Vehicle Braking
}

\author{
Mufti Reza Aulia Putra ${ }^{1}$ (1), Muhammad Nizam ${ }^{2,3,4, *}$, \\ Dominicus Danardono Dwi Prija Tjahjana ${ }^{1,3}$, Muhammad Aziz ${ }^{5}$ (D) and Aditya Rio Prabowo ${ }^{1}$ (D) \\ 1 Mechanical Engineering Department, Faculty of Engineering, Universitas Sebelas Maret, Jl. Ir. Sutami 36A, \\ Surakarta 57126, Indonesia; muftirezaauliap@student.uns.ac.id (M.R.A.P.); \\ ddanardono@staff.uns.ac.id (D.D.D.P.T.); aditya@ft.uns.ac.id (A.R.P.) \\ 2 Electrical Engineering Department, Faculty of Engineering, Universitas Sebelas Maret, Jl. Ir. Sutami 36A, \\ Surakarta 57126, Indonesia \\ 3 National Center for Sustainable Transportation Technology (NCSTT) ITB, Bandung 40132, Indonesia \\ 4 Lithium Battery Research and Technology Centre, Universitas Sebelas Maret, Jl. Slamet Riyadi 435, \\ Surakarta 57146, Indonesia \\ 5 Institute of Industrial Science, The University of Tokyo, Tokyo 153-8505, Japan; maziz@iis.u-tokyo.ac.jp \\ * Correspondence: muhammad.nizam@staff.uns.ac.id
}

Received: 6 June 2020; Accepted: 2 July 2020; Published: 6 July 2020

\begin{abstract}
The braking system in a vehicle has the main role of slowing down the speed or stopping the moving vehicle. Compared to mechanical braking, which utilizes friction, non-contact braking has several advantages, including longer lifetime and less maintenance. One form of non-contact braking systems is the eddy current brake (ECB), an electric braking system that employs eddy currents to operate. This research focuses on the impact of magnetic field sources used in the ECB. In addition, the number of magnetic field sources is also observed. In order to achieve an ECB design that can be easily applied in any types of vehicles, including motorcycles and compact cars, a compact ECB design with an excellent braking torque is required. In this study, a compact design of the ECB is obtained by distributing the required braking torque from the disc brake into multiple electromagnets. Finite element method-based modeling has been performed to study ECB parameters, including the number of coil winding, the number of electromagnets, and the electric current. The results of this study show that the developed compact ECB could produce $93.66 \%$ of the torque required for braking.
\end{abstract}

Keywords: contactless braking system; eddy current brake; multi polar eddy current brake

\section{Introduction}

The main role of the braking system is to decrease the speed of a moving vehicle or stop the vehicle. Braking can also be used to maintain the vehicle's position in its state. During its usage, the brake absorbs the kinetic energy, and the drag force to stop the objects is provided by friction. The absorbed energy is then transformed into heat [1]. Good braking performance is crucial for maintaining vehicle speed and vehicle safety.

The use of the mechanical braking system produces heat that must be released through cooling using its surrounding free air. Brakes that are used frequently can generate an amount of heat that is larger than the ability of the system to release it. The increase in heat decreases the braking performance, and a high temperature can eliminate braking forces, resulting in braking failure. The use of friction in this braking system has disadvantages. Brake components require maintenance and replacement at certain times. The service life of brake components can be increased by combining braking systems. Mechanical braking supported by engine brakes produces an excellent braking performance and leads 
to the extended service life of the braking components [2,3]. A conventional braking system generally employs a hydraulic system to generate sufficient drag force. This kind of braking system faces several problems, including a delay in braking time, wear of the brake pad, a low braking performance in the high-speed region, and bulkiness in size.

Electric and hybrid vehicles have been massively produced and adopted [4,5]. Electric vehicles show better energy efficiency and are more environmentally friendly. Different to conventional vehicles, electric vehicles employ no engine brake, and regenerative braking is adopted in order to substitute the engine brake. It is used as a support for braking and, additionally, to produce electricity [6,7]. The generated electricity is then utilized to charge the battery.

In order to solve the problems of a friction-based braking system and to provide an excellent braking performance even in the high-speed region, a contactless braking system has been developed. This kind of braking system is believed to have a longer lifetime and require less maintenance. One form of contactless braking system is the eddy current brake (ECB). The ECB is an electric braking system that employs the eddy currents principle. The main components of the ECB consist of a magnetic field in the exitation winding and brake caliper and conductor sources, as shown in Figure 1. An eddy currents is an induction current that is formed in the conductor section to produce braking force. The ECB can be combined with regenerative braking to improve energy efficiency [8]. In addition, the ECB can also be adopted as a braking support system. Furthermore, compared to using resistive loads on regenerative braking, the ECB has a superior braking performance because the torque components produced by the ECB are more effective in terms of braking performance [9].

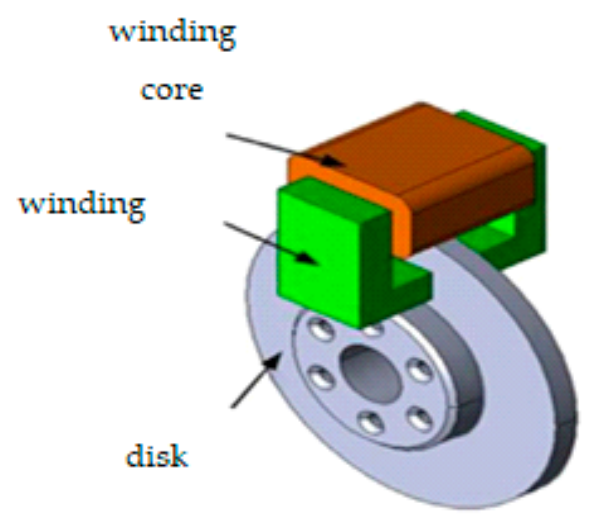

(a)

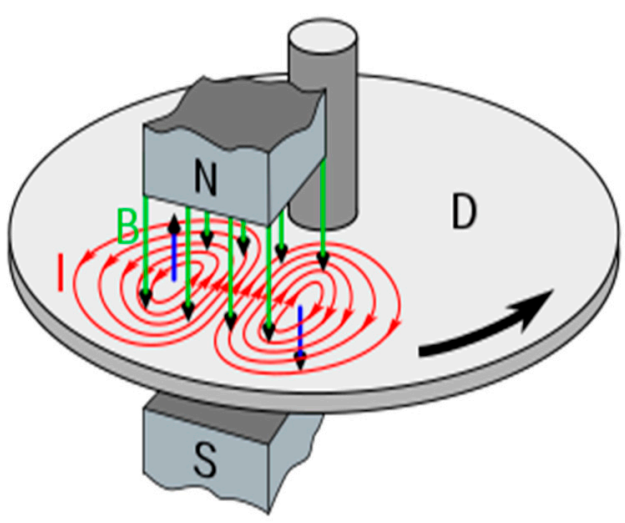

(b)

Figure 1. Axial unipolar eddy current brake (ECB): (a) design unipolar ECB; (b) eddy currents.

The ECB has been widely used in various scientific and application fields. It is generally used to improve braking performance and reduce the risk of mechanical failure. It can be applied to wind turbines as a turbine speed control system, so the rotation speed can be suppressed such that it is lower than its critical speed [10]. In addition, the ECB can be used in high-speed vehicles that have a low risk of failure, such as planes and trains. There are also several studies evaluating its application in light vehicles such as cars and motorbikes [11,12].

The improvement in ECB performance can be carried out by increasing the density of the magnetic field in the air gap. In general, inductance receives the magnetic field from one side. However, recent research shows that the use of magnetic fields from both sides can increase the magnetic field density [13]. The changes in the air gap have been evaluated in [14]. It was shown that a change in the gap effect generated the braking performance. This study focused mainly on the magnetic field density produced by air gaps, but the researchers did not pay attention to the influence of the magnetic field. Another study stated that the change in the position of the magnetic field affects the braking performance [15]. These changes indicate that changes in the location of the shoe pole result in the change of braking performance by the ECB. 
The limitation of using the ECB at low speeds is due to the induced currents, in which the magnitude is affected by the speed. To improve this performance, the ECB can be integrated with other systems that can provide braking at low speeds. Obara et al. [16] investigated hybrid braking, combining the ECB and the magnetic track brake. The ECB can provide good braking at high speeds and reduce mechanical contact, therefore reducing the possibility of braking system failure. At low speeds, the braking system uses magnetic track braking, which uses braking pads coated with braking material. A similar study was also carried out by Li et al. [15]. They combined the ECB with mechanical braking using a hydraulic system. The distance between the magnetic field source and the rail uses an electrically controlled hydraulic system. Furthermore, Ma et al. [17] developed the system by adding the design optimization using non-magnetic barriers to reduce the flux leak age. Providing a barrier to leakage increases the density of the magnetic field in the air gap and increases the braking force. Ryoo et al. [18] examined the current settings to obtain the optimal braking torque.

To activate the ECB, an external source of electricity and/or a permanent magnet are necessary, leading to a high total cost. To overcome these issues, an ECB system in which the source of the magnetic field is generated not by a permanent magnet but by an electromagnet from the electricity generated from a pack battery has been made. This system can save energy and reduce costs, as has been studied by Bae et al. [1]. A self-generation system to improve energy efficiency was also evaluated by Cho [2] by adopting capacitors. The capacity of the capacitor seemed to influence the energy efficiency.

Previous studies have examined how to improve performance without consideration of the size of the magnets used. The results of the existing studies show improvements in performance without considering the limitations of the size of the vehicle used. Unipolar research is still limited to the use of one magnet. There has been no research on the use of more than one magnetic field source with a unipolar design. This research further analyzes the effect of certain parameters. The magnetic field is generated by using an electromagnet, allowing for the possibility of controlling the current. This research focuses more on the study of the ECB braking system by making changes to the source of the magnetic field that is adopted. In addition, the use of more than one magnetic field sources is also evaluated further in this study. Both experimental and calculation analyses are conducted to validate the result. The purpose of this research is to make a good ECB for hybrid applications with conventional brakes for a lightweight vehicle. The ECB does not replace the conventional brake but supports it, so that increases the lifetime of conventional brakes.

\section{Literature Review}

An eddy currents is an induced current generated due to changes in the magnetic field in the conductor. Eddy currents can appear in a stationary conductor that is affected by the changing magnetic field or the moving object across the fixed magnetic field. Initially, the magnetic field is induced in the direction of its main magnetic field; therefore, there is a repulsive force between the two. Furthermore, another magnetic field that is opposite to the source of the main magnetic field is obtained, resulting in tensile force. Both generated forces produce another force in the opposite direction to the direction of the motion of the magnetic field [19].

The main components of the ECB consist of magnetic field sources and inductance. Based on its structure, the ECB can be categorized into axial, radial, linear, and retarder types. In this research, a unipolar design of the ECB is developed and evaluated. The unipolar design has advantages over other ECB designs [13]. By adopting the electromagnet, it is possible to achieve a braking performance that is easier to control compared to a permanent magnet. The magnetic field is produced by an electrically wound coil. The amount of magnetic flux produced by a coil depends on the amount of electric current flowing to the system. The amount of torque is regulated by changing the amount of current. Greater electric power leads to a greater magnetic field. In addition, the frequency and shape of the current signal also affect the braking performance. It was also found that the braking torque can be increased by adopting AC power [14]. However, one of the challenges faced by the ECB is that it is difficult to control in the low speed region. 
Increasing the braking capacity can be achieved by increasing the strength of the magnetic field source. Permanent magnets have a fixed capacity depending on the material used to make permanent magnets, such that the strength that can be obtained can no longer be increased, whereas the conductive winding has a limited capacity of strong electric current that can be produced. On the other hand, the limitations on the conductor material due to surface forces cause the limited volume of the area to be affected by the main magnetic field producing the eddy currents.

In addition to determining the design parameters, increasing the ECB braking torque can be achieved by making modifications. The amount of braking torque is directly proportional to the density of the magnetic flux in the air gap, so the braking torque can be increased by increasing the addition of permanent magnets as an additional magnetic field source. Yazdanpanah (2015) [9] uses two magnetic field sources simultaneously. Permanent magnets are at once used as a winding core. The resulting braking torque is higher than that of the $\mathrm{ECB}$, with a coil magnetic field source at the same current. This design has the disadvantage that there is still braking, even though no current flows to the coil, as a result of the existence of permanent magnets as the coil's core. If one wants to eliminate the braking force, a current that is opposite the permanent magnetic pole must be provided. As a refinement of the design, permanent magnets are placed at the end of the coil core. Because the permanent magnet is at the end of the coil core, when the coil has no electricity, the resulting magnetic field flows to the coil core. When the coil is given a current, the permanent magnetic field will add to the strength of the magnetic field, which works to produce braking torque, because a parallel arrangement is arranged.

The magnetic field is produced by an electrically wound coil. The amount of magnetic flux produced by a coil depends on the amount of flowing electric current. The amount of torque is regulated by changing the amount of flowing current. The greater the electric power given, the greater the magnetic field produced. Setting the frequency and shape of the current signal also affects the performance. Speed and torque settings are for variations in the shape of the sine and square step signals $[10,13]$. The difficulty setting is at low speeds. Circuits can be made parallel and in series. Performing a series of settings obtained the performance as needed [5].

The braking torque in the ECB is strongly influenced by the skin effect. The increase in speed results in the increase of this skin effect. According to Sharif et al. [20], the skin effect variable must be added when calculating the braking torque. The performance of the ECB for braking has been reviewed by Sharif et al. [21]. The skin effect shows different impacts, depending on the thickness of the conductor. Schieber [22] conducted an ECB study on thin plate sheets and found that the skin effect was not significant. Singh et al. [23] conducted research on thick plates and evaluated the impact of skin effects. In thick conductors, the skin effect greatly affects the braking torque produced at high speeds.

\section{Modeling and Methods}

Modeling was carried out in order to evaluate the developed model and analyze the effects of operating parameters to the produced braking torque. The braking torque in the ECB system was obtained from the interaction between the main magnetic field and the magnetic field generated by the eddy currents. The amount of braking torque depends on the magnitude of the main magnetic field that produces the eddy currents. The eddy currents further produce a second magnetic field that affects the braking force. The main factors that influence the performance are the magnetic field strength in the air gap and the amount of eddy currents in the inductor.

The amount of braking torque can be calculated by using several approaches, including the eddy currents loss equation. The amount of braking torque is proportional to the magnitude of eddy currents losses that occurs in the inductor material. The determination of the amount of braking torque can also be applied by using the Lorentz force equation and the Maxwell stress equation.

\subsection{Developed Model}

Modeling was conducted using the finite element method (FEM) in a 3D model using Ansys: Maxwell 3D software. The 3D design of the braking system was performed by using the 3D Solid 
Works modeling software of SolidWorks, and the produced 3D modeling data were then exported to Maxwell 3D. Table 1 shows the basic specifications of the developed braking system, including the materials and geometry. Throughout the numerical calculation and experimental test, the air gap and disc thickness are fixed at 0.5 and $4 \mathrm{~mm}$.

Table 1. Basic specifications of the developed compact ECB system, including material and geometry.

\begin{tabular}{ccc}
\hline Variable & Unit & Value \\
\hline Pole shoe length & $\mathrm{mm}$ & 30 \\
Pole shoe width & $\mathrm{mm}$ & 12.5 \\
The total length of the coil core & $\mathrm{mm}$ & 248 \\
Distance of pole shoe to disk center & $\mathrm{mm}$ & 83.5 \\
Air gap & $\mathrm{mm}$ & 0.5 \\
Disk thickness & $\mathrm{mm}$ & 4 \\
Relative permeability of aluminum & - & 1.000022 \\
Relative permeability of steel & - & 400 \\
Conductivity of aluminum & $\Omega \mathrm{m}$ & $2.06 \times 10^{-7}$ \\
\hline
\end{tabular}

Table 2 shows the parameters that are evaluated in this study, including the number of coil windings, the number of electromagnets, and the electrical current. These parameters are considered to significantly influence the generated magnetic field intensity. During the numerical calculation, the heat generated during braking is ignored. The disk brake is used as a rotor, while the electromagnet is adopted as the source of magnetic fields for the braking system. In order to validate the model, a validation test is initially conducted, and its results are explained in Section 4.

Table 2. Evaluated parameters during the modeling and numerical calculation.

\begin{tabular}{ccc}
\hline Parameters & Unit & Values \\
\hline Number of coil winding & - & $360,540,720$ \\
Number of magnet & - & $1,2,4$ \\
Electrical current & A & $20,25,30,35,40$ \\
\hline
\end{tabular}

Figure 2 shows the basic designs of the used disk and coil core during the validation test and numerical calculation. These designs are based on the general designs of a motorcycle disk brake. The disk brake uses non-ferrous material, which has a good performance as an ECB disk. The size of the coil core is also adjusted based on the size of the vehicle brake caliper; therefore, it can be applied to motorcycles. The design of the ECB uses different brackets from the conventional brake caliper. Therefore, if the conventional brake operates, the conventional brake does not affect the ECB parameter performance in terms of the position and the air gap.

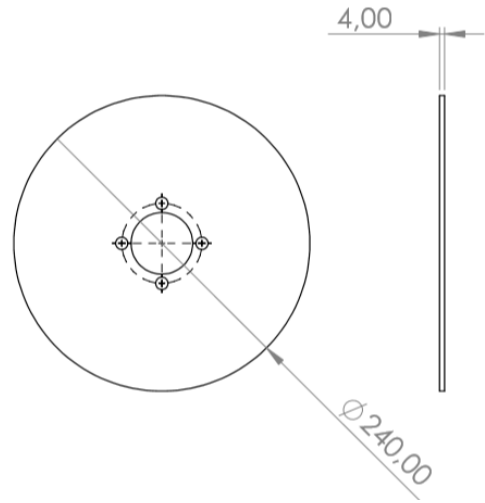

(a)

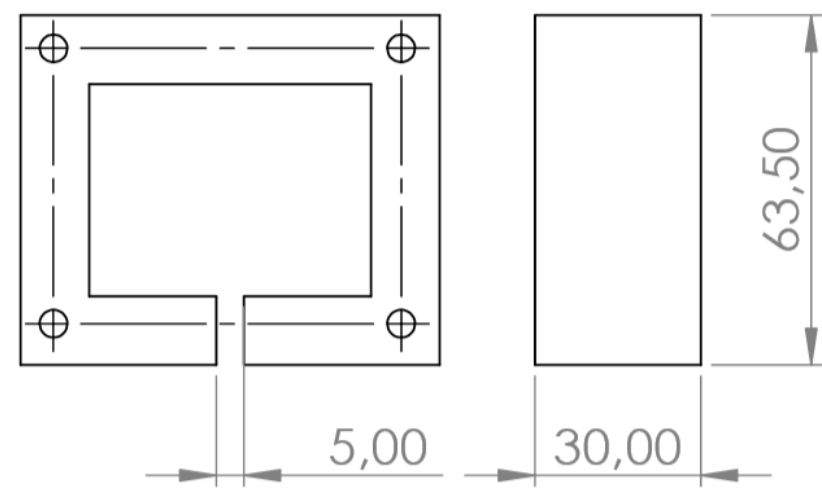

(b)

Figure 2. Designs of the used (a) disk and (b) magnet. 
The numerical calculation was carried out with the objective of obtaining the data in the form of braking torque produced by the ECB under different evaluated parameters. The data are used to determine the characteristics of the variables toward the optimum design of the brake. Before conducting the analysis, the clarification of the required braking conditions and the calculation of the required braking torque were conducted. The braking conditions were determined as the braking required to reduce the speed of a vehicle with a weight of $100 \mathrm{~kg}$ (assumed as motorcycle) and two wheels from 17 to $5.6 \mathrm{~m} / \mathrm{s}$, in a deceleration distance of $50 \mathrm{~m}$. In addition, the disc has a diameter of $120 \mathrm{~mm}$ [24]. From this braking condition, it is clarified that the required torque to reduce the speed from 17 to $5.6 \mathrm{~m} / \mathrm{s}$ is $52.1 \mathrm{Nm}$.

\subsection{Governing Equations}

The approach to producing the braking torque is to calculate the amount of braking force multiplied by the ECB radius. Because of the braking force that occurs due to electromagnetic interactions, the amount of braking force can be calculated using the Lorentz force. The magnitude of the force is calculated from the magnitude of the magnetic field and the current flowing at a certain volume and can be written in Equation (1):

$$
\vec{F}_{d}=\int_{v} \vec{J} \times \vec{B} d V
$$

Volume can also be calculated using the surface area with double integrals. The amount of braking torque can be written by multiplying the braking force with the radius of the drum, as Equation (2):

$$
T_{b}=\iint_{S} r_{p} \times(J \times B) d S
$$

The magnitude of the magnetic field strength can also be written with the density of the magnetic field per unit area, or $B=\Phi / A$. Hence, the braking force equation can be written as Equation (3):

$$
F_{R}=I_{R, i} \cdot l_{R, e, i} \cdot \varnothing_{R, i} / A_{R, m, i}
$$

The amount of eddy currents is calculated by Lorentz's force equation:

$$
J=\sigma(E+v+B)
$$

The magnitude of the eddy currents is influenced by the presence of magnetic fields and electric fields [25-35]:

$$
\begin{gathered}
F=\left.\frac{I_{\delta} p}{2 \mu_{0}} \int_{0}^{2 t} \operatorname{Re}\left(B_{2 x} \bar{B}_{2 y}\right)\right|_{y=0} D x \\
F=\frac{1}{2 \mu_{0}} \int_{0}^{2 t_{p}} \operatorname{Re}\left(B_{1 x} B_{1 y}\right) D x
\end{gathered}
$$

where $\mu_{0}$ is the air permeability. The magnitude of the magnetic field is different from that proposed by Jang et al. [11] because the magnitude of the magnetic field is sought using magnetic vector potential techniques:

$$
F_{a b}=\sum_{n=1, o d d}^{\infty} \frac{\omega_{p} p}{2 \mu_{0}} \int_{0}^{2 x} \operatorname{Re}\left(B_{m x} B_{m y}\right) d x
$$

The calculation of the braking system using the disk brake design can be shown by the equation as stated by Shin et al. [36] and Choi et al. [6]:

$$
F_{b}=\frac{1}{2 \mu_{0}} \int_{0}^{2 \pi} \int_{R_{i}}^{R_{0}} \operatorname{Re}\left[B_{\theta}^{I I I}(r, \theta, d+g) \cdot\left\{B_{z}^{I I I}(r, \theta, d+g)\right\}\right] e d r d \theta
$$


The formulation to obtain the value of the braking torque is calculated from the magnitude of the magnetic field, which affects the conductor or the magnetic flux density of the air gap. The use of only mathematical analytics results in an inaccurate calculation because it does not take into account the geometry of objects. The advantage of using analytical methods is the speed in calculation and te simplicity of the equation used. On the other hand, numerical analysis using FEM produces results that have a good agreement to the real conditions, because the numerical analysis takes into account the object geometry.

\section{Experimental Validation}

\subsection{Configuration of the Test Bed}

Experiments were carried out using a test table that has been designed as an ECB test tool. Figures 3 and 4 show a schematic of the experimental setup and a picture of the actual setup, respectively. Essentially, the test table had the same specifications as those in the numerical calculation. The current source used was a voltage rectifier (Lakoni, Falcon 120 E 900 W 120 E inverter, China). The given current was measured using AC/DC clamp meters (Krisbow, KW 0600491, Kawan Lama Grup, Indonesia), while braking force was identified by using a single point load cell. The brushless dc motor (qs motor, $3000 \mathrm{~W} 13870 \mathrm{H}$, China) was used as the driving source. The influence of the temperature was disregarded in this experimental work. Table 3 shows the additional conditions used during the experimental test.

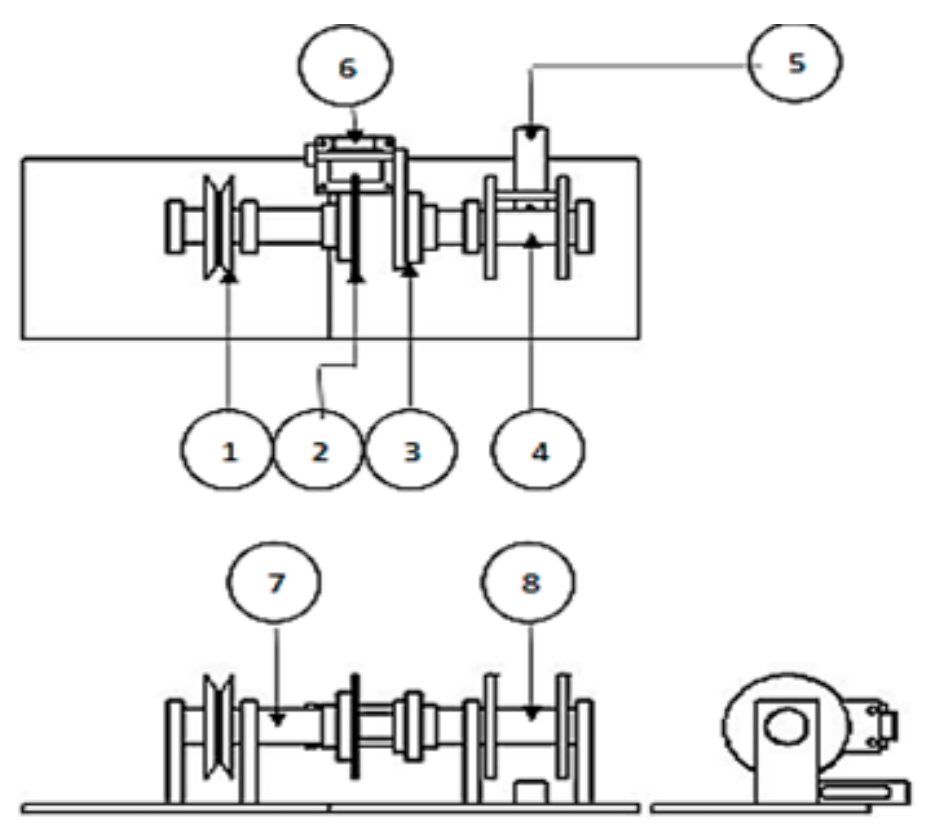

Figure 3. Experimental setup: (1) pulley; (2) disk; (3) bracket; (4) stopper; (5) load cell; (6) electromagnet; (7) power; (8) magnet.

Table 3. Additional conditions used during the experimental test.

\begin{tabular}{ccc}
\hline Variable & Unit & Value \\
\hline Electrical current & $\mathrm{A}$ & 20 \\
Number of coil windings & - & 360 \\
Number of magnet & - & 1 \\
\hline
\end{tabular}

The electric motor is set to operate at a given speed. The experimental test is carried out by activating the ECB with a current of $20 \mathrm{~A}$. After the current is given, the braking test is conducted. 
During the braking process, the speed is kept constant at a certain value. It is intended that the load measured by the load cell matches the desired speed.

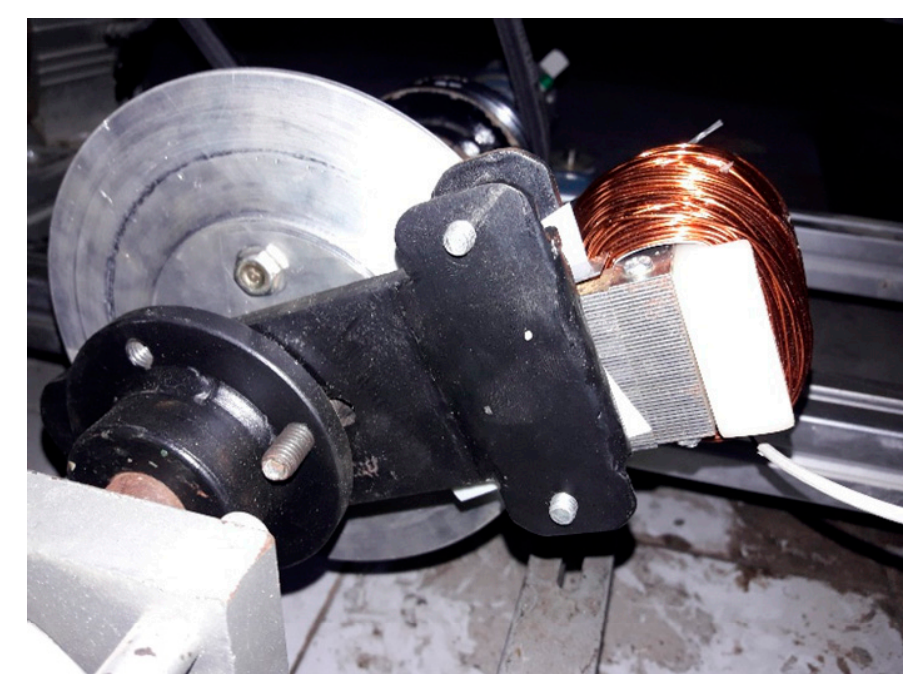

Figure 4. Picture of the used experimental test table.

Experiments were conducted using a relatively simple principle. Figure 5 provides a schematic flow of the experimental process. The rotation speed is set at the desginated speed (150-750 rpm), and the motor torque is delivered to the disk brake through the shaft. During the braking, an electric current is passed to the winding coil in the electromagnet. The generated magnetic field will interact with the disc and create the braking force. The resulting braking force is measured using the load cell, and its obtained data are then displayed on the LED display.

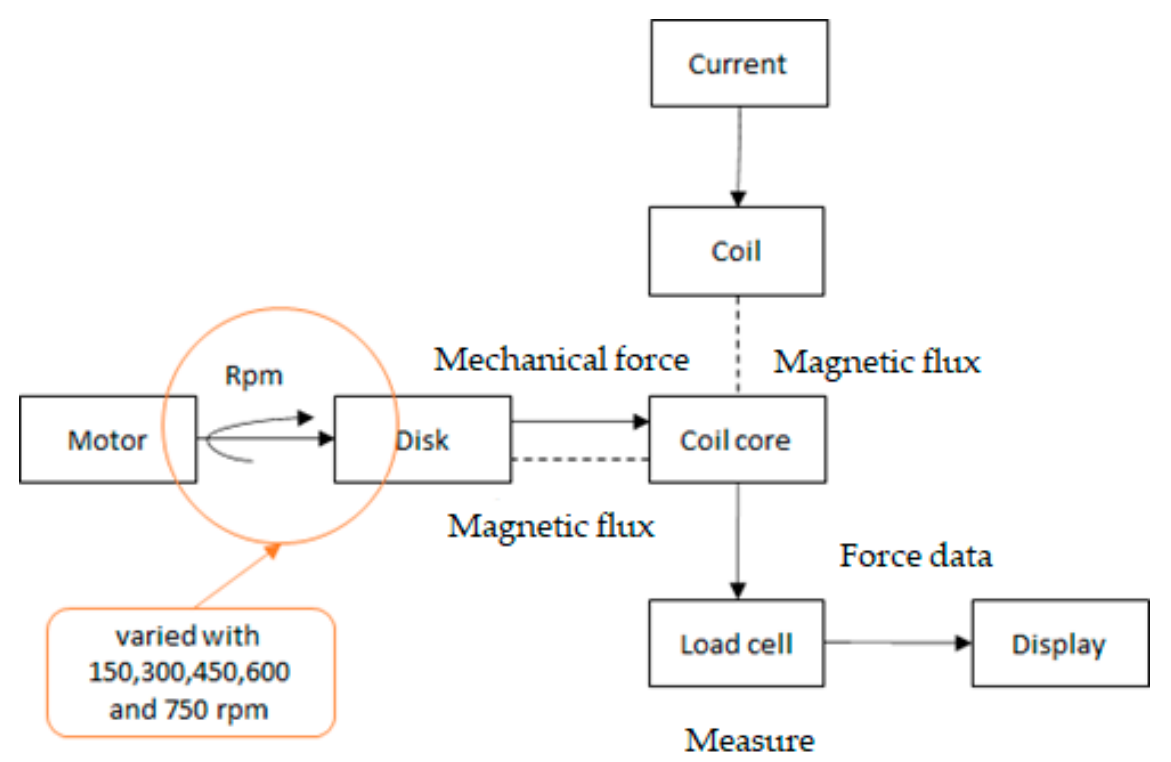

Figure 5. Schematic flow of the experimental test.

\subsection{Results of Experimental Test}

\subsubsection{Results of Experiments}

Figure 6 shows the correlation of the rotation speed and the torque obtained from the experimental test. The rotation speed is set in the range of $150-750 \mathrm{rpm}$ with an interval of $100 \mathrm{rpm}$. As can be observed in Figure 6, the rotation speed influences the required braking torque, and a higher rotation 
speed tends to require a higher braking torque. However, the required braking torque is maximum at $600 \mathrm{rpm}$ and tends to decrease slightly when the rotation speed is increased. This phenomenon is considered due to the skin effect, which influences the sensing during measurement. The characteristics of the ECB using aluminum conductor material are such that, if the air gap changes, there will be a shift in the value of the critical velocity caused by changes in current density. When the critical speed point is exceeded, brake torque is reduced. This is caused by the emergence of the magnetic field concentration on the outside (skin effect).

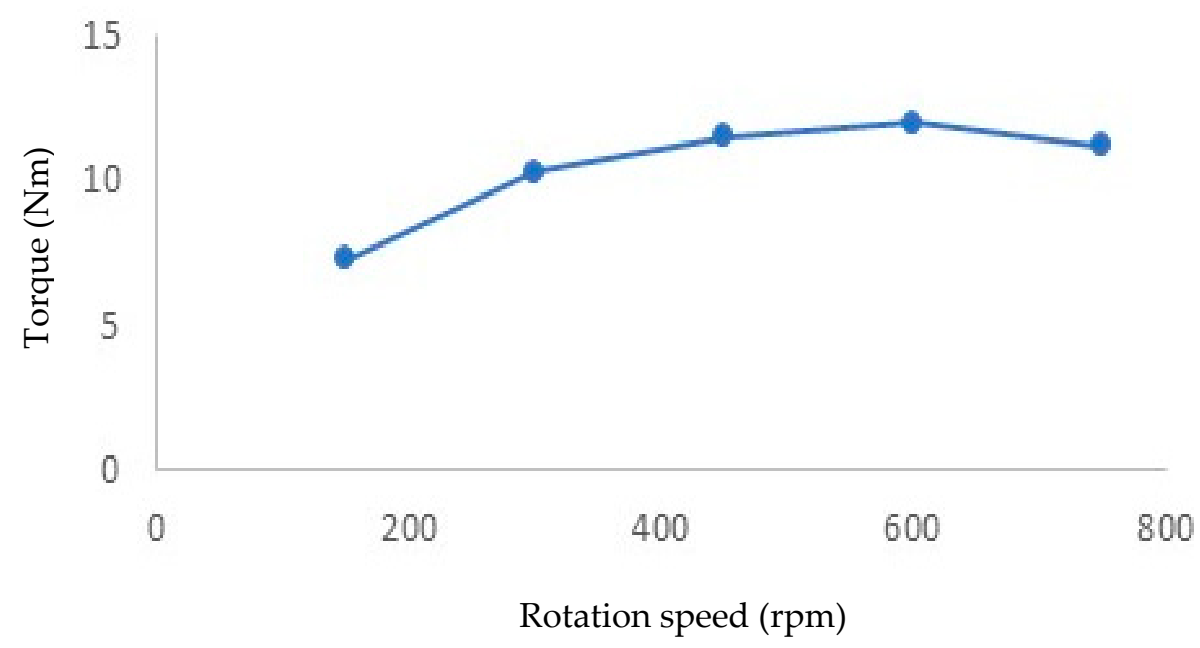

Figure 6. Correlation between the rotation speed and torque during the validation test.

\subsubsection{Comparison of Experimental Data and Numerical Calculation}

Table 4 shows the comparison of experimental data and numerical calculation conducted based on FEM. In general, the average errors of the braking torque for each rotation speed between the experiments and numerical calculation are very small (almost below $5 \%$ ). These different values are considered due to several aspects, including the coil temperatures and heat generation during the braking process. In addition, it is difficult to maintain the rotation speed of the electric motor as a constant when braking occurs. Moreover, the vibrations affect the load cell readings, as well as the material of the brackets used in the electromagnet. As the error value is very small (below $5 \%$ ), it is believed that the data generated by the numerical calculation are valid.

Table 4. Comparison of experimental data and numerical calculation conducted based on the finite element method (FEM).

\begin{tabular}{cccc}
\hline \multirow{2}{*}{ Rotation Speed (rpm) } & \multicolumn{2}{c}{ Torque (Nm) } & \multirow{2}{*}{ Error Difference \% } \\
\cline { 2 - 3 } & Experiment & FEM & \\
\hline 150 & 7.3 & 6.97 & 4.52 \\
300 & 10.3 & 10.92 & 6.01 \\
450 & 11.5 & 12.03 & 4.6 \\
600 & 12 & 11.67 & 2.75 \\
750 & 11.2 & 10.69 & 4.5 \\
& Average error $(\%)$ & & 4.476 \\
\hline
\end{tabular}

\section{Calculation Results and Discussion}

\subsection{Corelation of Braking Torque and Rotation Speed}

The braking torque at the ECB is strongly influenced by the skin effect, which is also increased by the increase in rotation speed. This is indicated by the tendency of the stronger generated magnetic field, resulting in the changes in flux density. The skin effect can be described as the phenomenon of 
electron accumulation in a conductor, which is concentrated in the conductor's skin. The presence of a skin effect results in an increase in current density in the farthest part of the conductor core, as shown in Figure 7.
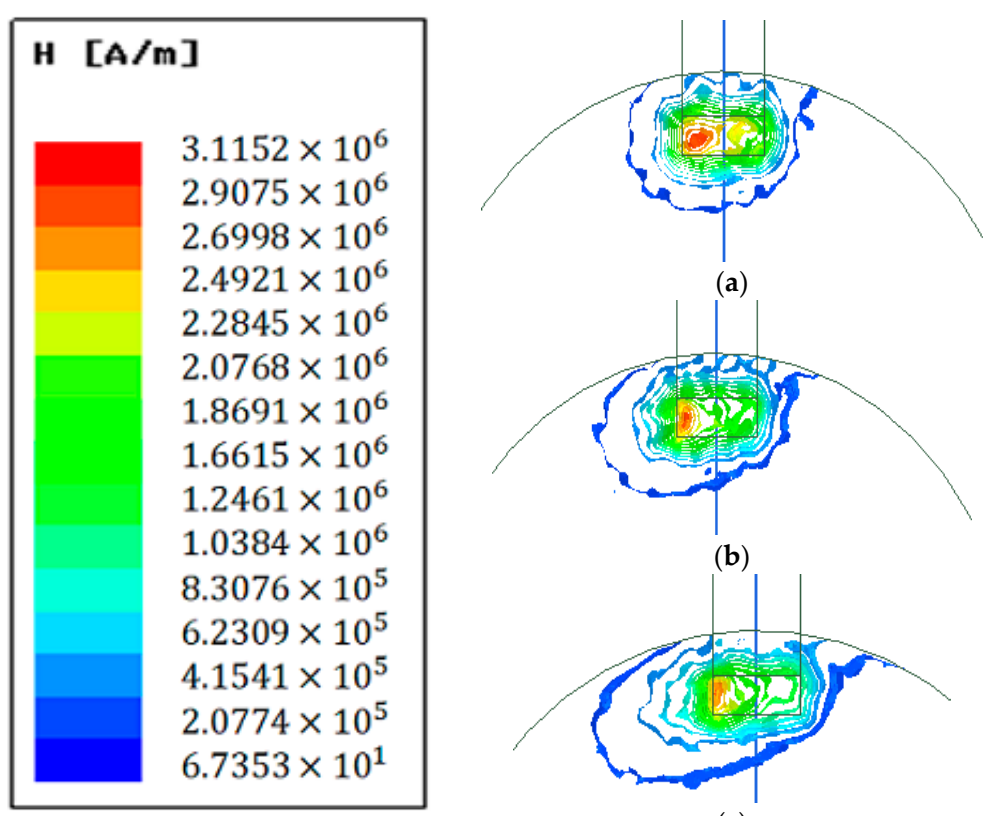

(c)

Figure 7. Magnetic flux density change at different rotation speeds: (a) $150 \mathrm{rpm}$; (b) $450 \mathrm{rpm}$; (c) $750 \mathrm{rpm}$.

From Figure 8, it is clear that a higher rotation speed results in an increased skin effect. This skin effect causes a decrease in the braking torque at high speed. When the rotation speed is $150 \mathrm{rpm}$, the magnetic field generated on the disk is still in the area close to the source of the magnetic field. However, as the rotation speed is increased to 450 and $750 \mathrm{rpm}$, the generated magnetic fields are distributed at the area outside of the magnetic field source. It seems that the rotation speed of $450 \mathrm{rpm}$ is the critical speed in this developed design. The secondary magnetic field for this rotation speed is higher than the one of lower rotation speed but still centralized near to the magnetic field source. Meanwhile, at a rotation speed of $750 \mathrm{rpm}$, the braking torque begins to decrease due to the distribution of the secondary magnetic field.

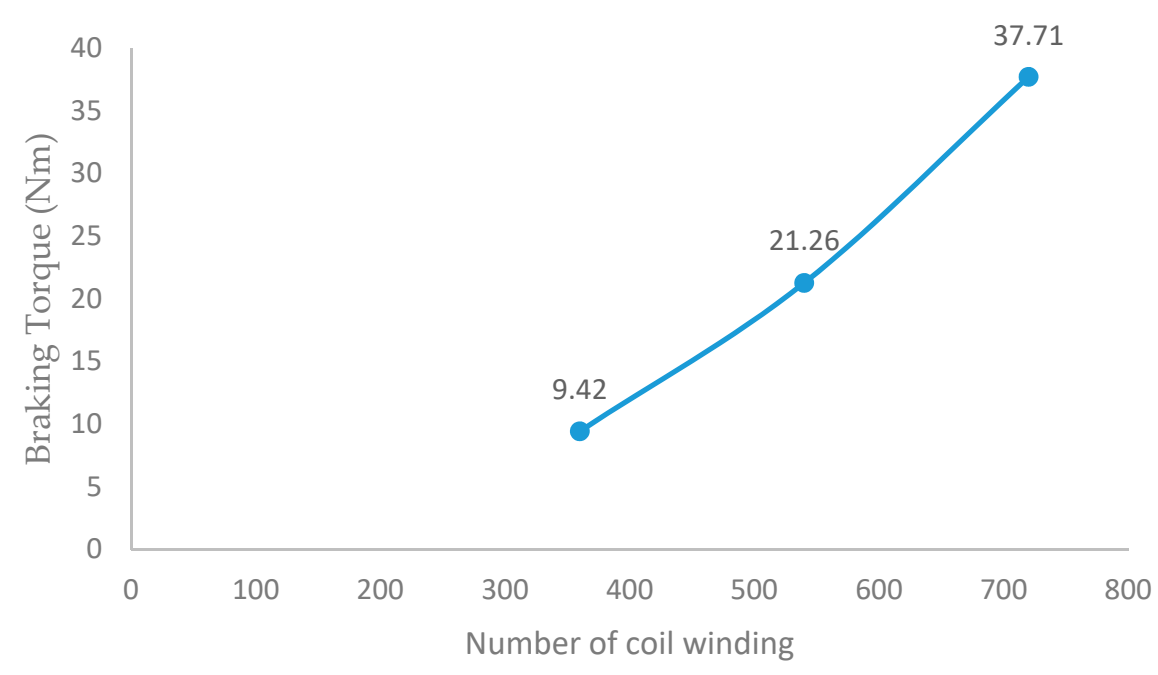

Figure 8. Effects of the number of coil windings on the braking torque. 


\subsection{Increase in Magnetic Field}

Based on experimental tests and numerical calculations, the highest torque value was obtained at $12 \mathrm{Nm}$ from the experimental process using a reference-based design. In reality, the braking requirement can be defined by using the braking torque in order to reduce the vehicle speed. In this case, the braking torque is calculated as the torque required to reduce the vehicle speed from 17 to $5.6 \mathrm{~m} / \mathrm{s}$, and it is $52.1 \mathrm{Nm}$. Therefore, the use of the ECB can reduce $23 \%$ of the braking torque required by the braking system. It is considered that there are several ways to improve the performance of the ECB and still retain the compactness of the system, including the number of coil windings, the number of electromagnets, and the electric current; therefore, the ECB can be applied for light vehicles including motorcycles. The influences of these parameters are analyzed and shown in this sub-section. The numerical simulation for analyzing these parameters was conducted under the conditions of an air gap and rotation speed of $1 \mathrm{~mm}$ and $450 \mathrm{rpm}$, respectively.

The magnetic field is generated by using a coil that is powered by an electric current. The amount of magnetic flux produced by a coil depends on the amount of electric current given. Therefore, the amount of required torque can be regulated by changing the amount of electric current.

Figure 8 shows the correlation of the number of coil windings and the generated braking torque. An increase in coil windings results in a higher braking torque. However, this increase in coil windings also resulted in a larger system size. In addition, Figure 9 shows the correlation of electric current and generated braking torque. Similar to the effect of the number of coil windings, a high electric current also leads to a higher braking torque. Unfortunately, a higher electric current potentially causes an increase in heat during braking, leading to a risk of overheating. Both the number of coil windings and the electric current clearly influence the braking torque [30], and it is important to set optimum values for each braking system.

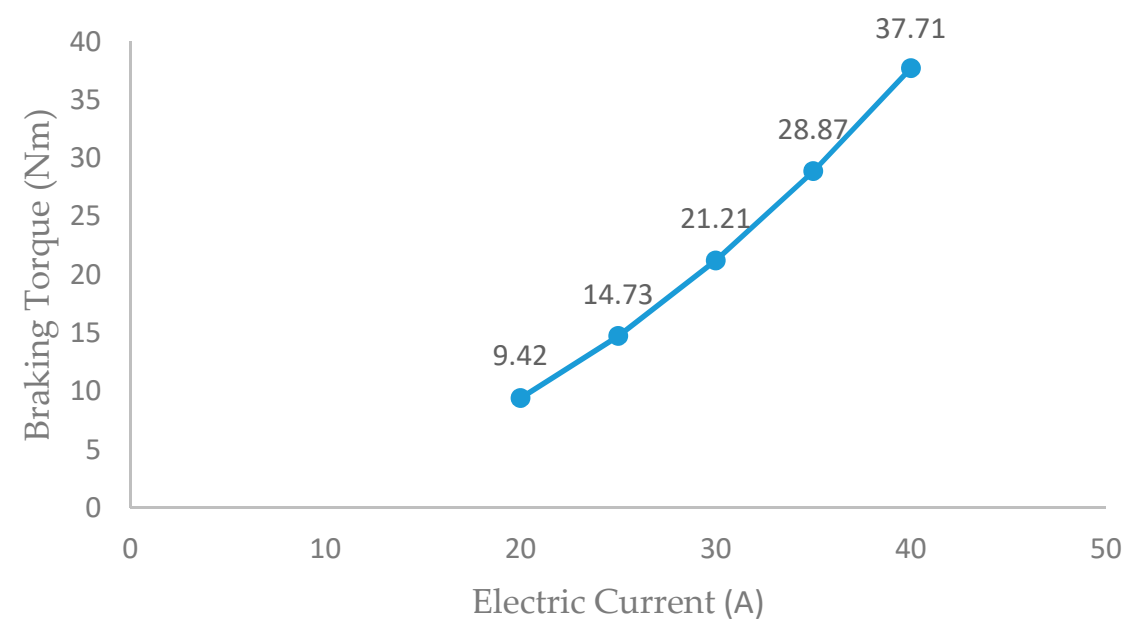

Figure 9. Effect of electric current on the braking torque (where the number of coil windings is fixed at 360).

The number of electromagnets is also considered to potentially improve the braking performance. In this study, difference numbers of electromagnets were analyzed, starting from one to four electromagnets. Figure 10 shows the configuration of the magnet used during numerical calculation.

Figure 10 shows the correlation between the number of electromagnets and the generated braking torque. It is clear that the increase in the number of magnet significantly improves the braking torque. Figure 11 shows the obtained contours of the magnetic field for two- and four-magnet configurations. By increasing the number of electromagnets, the distribution of the magnetic field throughout the disc brake becomes larger. By increasing the number of electromagnets, the size of each braking unit can be kept small and compact, while fulfilling the required braking torque. 


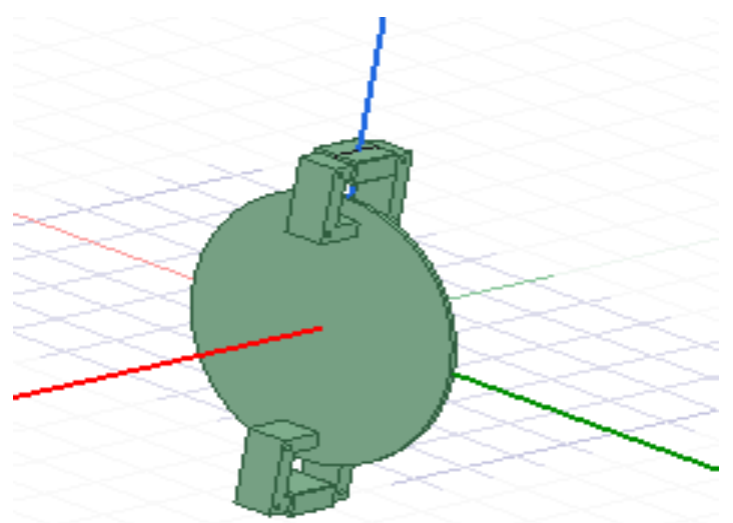

(a)

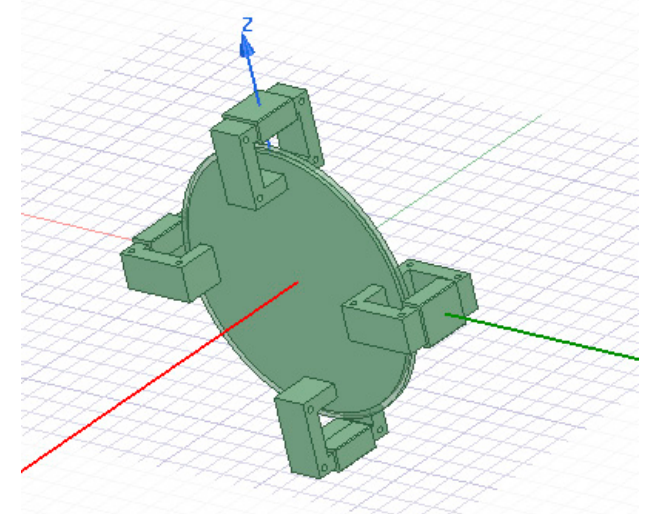

(b)

Figure 10. Developed compact ECB designs with (a) two electromagnets and (b) four electromagnets.

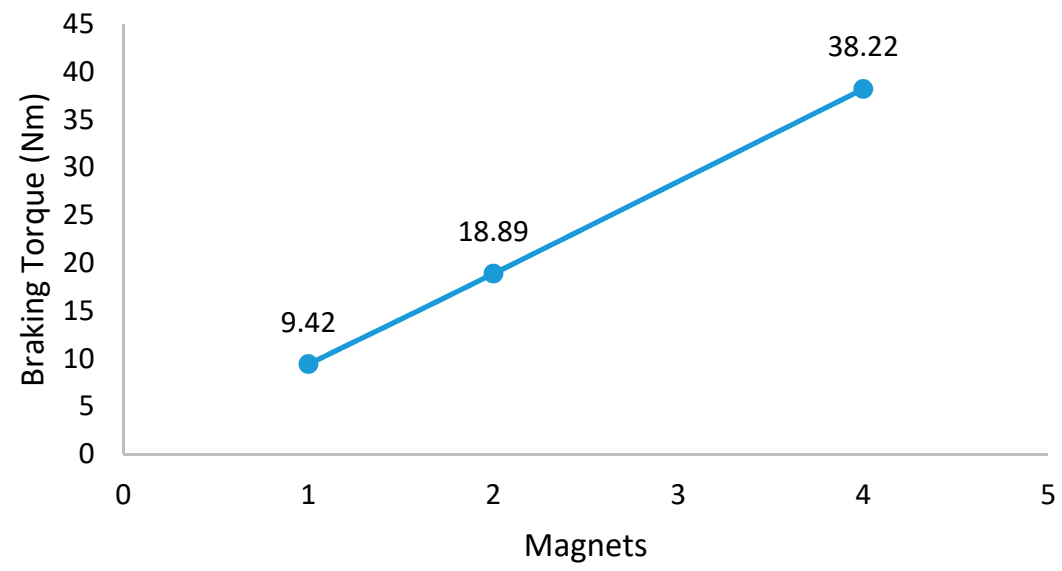

Figure 11. Correlation between the number of electromagnets and the braking torque with 20A and 360 coils.

It is important to note that the increase in the number of electromagnets should avoid any interaction risk of the magnetic field generated by each magnet. In addition, it is necessary to consider the space left for the installation of conventional braking systems. As shown in Figure 12, although using four electromagnets, the interaction of the magnetic field among the poles can be avoided. The interactions of the magnetic field can result in magnetic field leakage. The use of four electromagnets can generate a 48.8-Nm braking torque. In addition, reducing the vehicle's speed from 60 to $20 \mathrm{~km} / \mathrm{h}$ requires $52.1 \mathrm{Nm}$ (a vehicle weight of $100 \mathrm{~kg}$ ). The use of the ECB with this design can reduce $93.66 \%$ of the braking torque required by the braking system compared to without an ECB. By flowing an electric current of $30 \mathrm{~A}$, setting the number of coil windings to 540, and using two electromagnets, a higher braking torque than is required can be generated.

Looking at Figure 13, it is important to note that the ECB does not replace conventional brakes. The ECB is used as an additional part for the braking system of a lightweight vehicle. The braking distances will be relatively similar whether an ECB is used or not. It is important that the ECB will be used in the speed range of medium to high. Therefore it will decrease the use of conventional brakes and thus will increase its life since the heat during braking operation, and the wear of the brake pads will be reduced. 


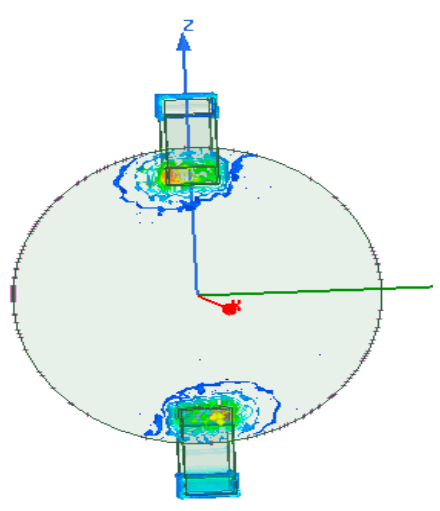

(a)

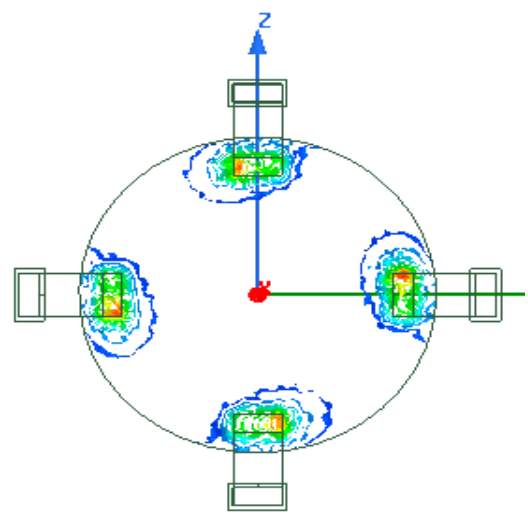

(b)

Figure 12. Obtained contours of the magnetic field: (a) two electromagnets and (b) four electromagnets.

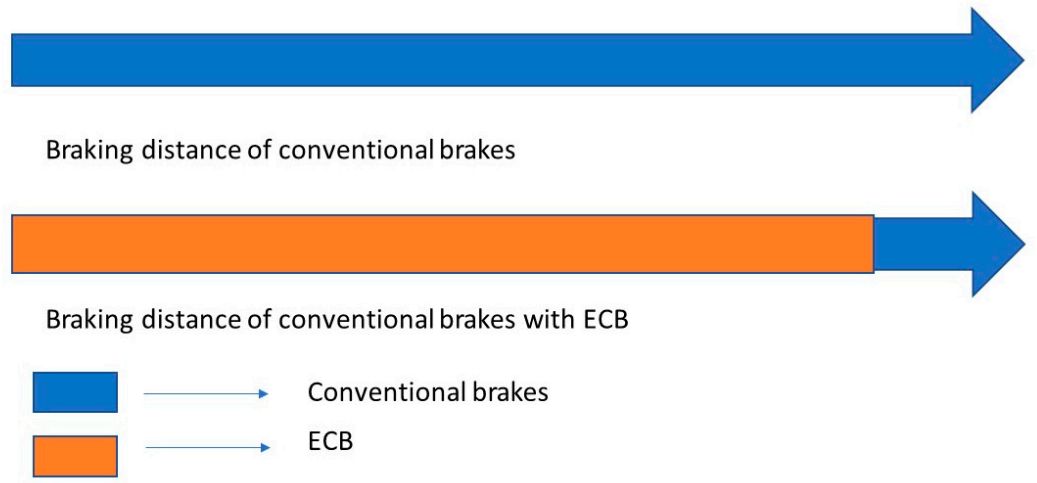

Figure 13. Braking distance of the conventional brakes and the conventional brakes with ECB.

\section{Conclusions}

In this work, braking torque analysis using the multi-polar ECB was performed with the objective of developing a compact ECB system and evaluating several parameters, including the number of coil windings, the number of electromagnets, and the electric current. Numerical calculation was conducted using 3D FEM. An experimental study was also conducted to validate the developed model. From the experimental test, the higher rotation speed tends to require a higher braking torque, although, due to the skin effect, it slightly decreases when the rotation speed is higher than the critical value.

The number of coil windings and the electric current also significantly influence the generated braking torque. A higher number of coil windings and an electric current generally increases the generated braking torque. In addition, the number of electromagnets also influences braking performance. By distributing the required braking torque into several braking units (electromagnets), the size of each braking unit can be kept compact, so it is applicable to any light vehicle, including motorcycles. As a further study, research related to efforts to clarify how the ECB can effectively and completely stop vehicles is required, in correlation with several parameters, to achieve the optimum design and performance of the ECB system.

Author Contributions: Conceptualization, M.R.A.P., M.A. and M.N.; methodology, M.R.A.P.; software, M.R.A.P.; validation, M.R.A.P.; formal analysis, M.R.A.P., M.N. and D.D.D.P.T.; investigation, M.R.A.P.; resources, M.R.A.P.; data curation, M.R.A.P.; writing-original draft preparation, M.R.A.P., M.A. and A.R.P.; writing-review and editing, M.R.A.P., M.A. and M.N.; visualization, M.R.A.P.; supervision, M.N.; project administration, M.N.; funding acquisition, M.N. All authors have read and agreed to the published version of the manuscript.

Funding: This research received no external funding.

Acknowledgments: This work was funded by the Ministry of Research, Technology, and Higher Education of the Republic of Indonesia, through contract no. 208/SP2H/AMD/LT/DRPM/2020. This research was partially funded by the Indonesian Ministry of Research, Technology, and Higher Education, under the World Class University Program, managed by the Institute of Technology Bandung, Indonesia. 
Conflicts of Interest: The authors declare that there is no conflict of interest.

\section{References}

1. Bae, J.N.; Kim, Y.E.; Son, Y.W.; Moon, H.S.; Yoo, C.H.; Lee, J. Self-Excited Induction Generator as an Auxiliary Brake for Heavy Vehicles and Its Analog Controller. IEEE Trans. Ind. Electron. 2014, 62, 3091-3100. [CrossRef]

2. Cho, S.; Jeong, T.; Bae, J.; Yoo, C.; Lee, J. Analysis and Performance of the Self Excited Eddy Current Brake. J. Electr. Eng. Technol. 2017, 12, 459-465. [CrossRef]

3. Zou, N.; Wang, Q.; Wang, W.; Zeng, X. Simulation Study of CVT Ratio Control for Engine Braking. In Proceedings of the 2009 International Conference on Measuring Technology and Mechatronics Automation, Zhangiiajie, China, 11-12 April 2009; IEEE: Piscataway, NJ, USA, 2009; pp. 367-370. [CrossRef]

4. Nizam, M.; Mohamed, A.; Hussain, A. Dynamic voltage collapse prediction on a practical power system using power transfer stability index. In Proceedings of the 2007 th Student Conference on Research and Development, SCORED, Selangor, Malaysia, 11-12 December 2007; p. 5. [CrossRef]

5. Sutopo, W.; Astuti, R.W.; Purwanto, A.; Nizam, M. Commercialization model of new technology lithium ion battery: A case study for smart electrical vehicle. In Proceedings of the 2013 Joint International Conference on Rural Information and Communication Technology and Electric-Vehicle Technology, rICT and ICEV-T, Bandung, Indonesia, 26-28 November 2013. [CrossRef]

6. Choi, J.Y.; Shin, H.J.; Jang, S.M.; Lee, S.H. Torque Analysis and Measurements of Cylindrical Air-Gap Synchronous Permanent Magnet Couplings Based on Analytical Magnetic Field Calculations. IEEE Trans. Magn. 2013, 49, 3921-3924. [CrossRef]

7. Day, A.J.; Newcomb, T.P. Dissipation of Frictional Energy from the Interface of an Annular Disc Brake. Proc. Inst. Mech. Eng. Part D Transp. Eng. 1984, 198, 201-209. [CrossRef]

8. Edwards, J.D.; Jayawant, B.V.; Dawson, W.R.C.; Wright, D.T. Permanent-Magnet Linear Eddy-Current Brake with a Non-Magnetic Reaction Plate. IEE Proc. Electr. Power Appl. 1999, 146, 627. [CrossRef]

9. Yazdanpanah, R.; Mirsalim, M. Design of Robust Speed and Slip Controllers for a Hybrid Electromagnetic Brake System. IET Electr. Power Appl. 2015, 9, 307-318. [CrossRef]

10. Gulbahce, M.O.; Kocabas, D.A.; Nayman, F. Investigation of the Effect of Pole Shape on Braking Torque for a Low Power Eddy Current Brake by Finite Elements Method. In Proceedings of the 2013 8th International Conference on Electrical and Electronics Engineering (ELECO), Bursa, Turkey, 28-30 November 2013; IEEE: Piscataway, NJ, USA, 2013; pp. 263-267. [CrossRef]

11. Jang, S.-M.; Lee, S.-H. Comparison of Three Types of Permanent Magnet Linear Eddy-Current Brakes According to Magnetization Pattern. IEEE Trans. Magn. 2003, 39, 3004-3006. [CrossRef]

12. Jee, I.H.; Nahm, S.Y.; Kang, S.J.; Ryu, K.S. A Magnetic Brake for Small Wind Turbines. J. Magn. 2012, 17, 33-35. [CrossRef]

13. Karakoc, K.; Suleman, A.; Park, E.J. Analytical Modeling of Eddy Current Brakes with the Application of Time Varying Magnetic Fields. Appl. Math. Model. 2016, 40, 1168-1179. [CrossRef]

14. Kim, Y.S.; Choi, Y.H.; Lee, J.M.; Noh, J.S.; Kim, J.J.; Bien, F. Fabrication of a Novel Contactless Switch Using Eddy Current Displacement Sensor for Safer Vehicle Brake System. IEEE Trans. Veh. Technol. 2011, 60, 1485-1495.

15. Li, P.; Ma, J.; Fang, Y. Design and Analysis of Hybrid Excitation Rail Eddy Current Brake System of High-Speed Train. In Proceedings of the 2011 IEEE International Conference on Service Operations, Logistics and Informatics, Beijing, China, 10-12 July 2011; IEEE: Piscataway, NJ, USA, 2011.

16. Obara, T.; Kumagai, N.; Takiguchi, T. Development of Hybrid Rail Brake. Proc. Inst. Mech. Eng. Part F J. Rail Rapid Transit 1995, 209, 61-65. [CrossRef]

17. Ma, J.E.; Zhang, B.; Huang, X.Y.; Fang, Y.T.; Cao, W.P. Design and Analysis of the Hybrid Excitation Rail Eddy Brake System of High-Speed Trains. J. Zhejiang Univ. Sci. A 2011, 12, 936-944. [CrossRef]

18. Ryoo, H.J.; Kim, J.S.; Kang, D.H.; Rim, G.H.; Kim, Y.J.; Won, C.Y. Design and Analysis of an Eddy Current Brake for a High-Speed Railway Train with Constant Torque Control; IEEE: Piscataway, NJ, USA, 2000.

19. Rodrigues, O.; Taskar, O.; Sawardekar, S.; Clemente, H.; Dalvi, G. Design \& Fabrication of Eddy Current Braking System. Int. Res. J. Eng. Technol. 2016, 3, 809-815.

20. Sharif, S.; Faiz, J.; Sharif, K. Performance Analysis of a Cylindrical Eddy Current Brake. IET Electr. Power Appl. 2012, 6, 661. [CrossRef] 
21. Sharif, S.; Sharif, K. Influence of Skin Effect on Torque of Cylindrical Eddy Current Brake. In Proceedings of the 2009 International Conference on Power Engineering, Energy and Electrical Drives, Lisbon, Portugal, 18-20 March 2009; IEEE: Lisbon, Portugal, 2009; pp. 535-539. [CrossRef]

22. Schieber, D. Unipolar Induction Braking of Thin Metal Sheets. Proc. Inst. Electr. Eng. 1972, 119, 1499. [CrossRef]

23. Singh, A. Theory of Eddy-Current Brakes with Thick Rotating Disc. Proc. Inst. Electr. Eng. 1977, 124, 373. [CrossRef]

24. Zhou, S.; Yu, H.; Hu, M.; Huang, L. Design of Permanent Magnet Eddy Current Brake for a Small Scaled Electromagnetic Launch Model. J. Appl. Phys. 2012, 111, 07A738. [CrossRef]

25. Kim, J.S.; Kim, S.M.; Jeong, J.H.; Jeong, S.C.; Lee, J.W. Effect of Regenerative Braking Energy on Battery Current Balance in a Parallel Hybrid Gasoline-Electric Vehicle under FTP-75 Driving Mode. Int. J. Automot. Technol. 2016, 17, 865-872. [CrossRef]

26. Luo, L.; Zhai, Q.; Li, W.; Qian, C.; Liu, H. Research on an Integrated Electromagnetic Auxiliary Disc Brake Device for Motor Vehicle. IEEJ Trans. Electr. Electron. Eng. 2017, 12, 434-439. [CrossRef]

27. Luo, N.; Jiang, J.; Yu, A. Research on the Control Strategy of the Regenerative Braking System. In Proceedings of the 2014 International Conference on Mechatronics and Control (ICMC), Jinzhou, China, 3-5 July 2014; IEEE: Piscataway, NJ, USA, 2014; pp. 2514-2517. [CrossRef]

28. Meier, S.; Hahn, I. Modeling Single and Double Stator Axial Eddy Current Brakes Considering Current Displacement, Magnetic Leakage, Fringing and Saturation Using Coupled Electric and Magnetic Equivalent Circuits. In Proceedings of the IECON Proceedings (Industrial Electronics Conference), Dallas, TX, USA, 29 October-1 November 2014; IEEE: Piscataway, NJ, USA, 2014; pp. 736-742. [CrossRef]

29. Shiau, J.K.; Ma, D.M.; Jou, M. Analysis and Experiments of Eddy Current Brakes with Moving Magnets. In Materials Science Forum; Trans Tech Publications Ltd.: Bäch SZ, Switzerland, 2008; Volume 575.

30. Singh, A.K.; Ibraheem. Model Development of Eddy Current Brakes for Energy Absorbing System. In Proceedings of the 2015 International Conference on Recent Developments in Control, Automation and Power Engineering (RDCAPE), Noida, India, 12-13 March 2015.

31. Smythe, W.R. On Eddy Currents in a Rotating Disk. Electr. Eng. 1942, 61, 681-684. [CrossRef]

32. Waloyo, H.T.; Nizam, M.; Putra, M.R.A. Characterization of Pole Location on Unipolar Axial Eddy Current Brake. In Proceedings of the 2019 6th International Conference on Electric Vehicular Technology (ICEVT), Bali, Indonesia, 18-21 November 2019; IEEE: Piscataway, NJ, USA, 2019; pp. 143-145. [CrossRef]

33. Waloyo, H.T.; Ubaidillah, U.; Tjahjana, D.D.D.P.; Nizam, M.; Koga, T. Mini Review on the Design of Axial Type Eddy Current Braking Technology. Int. J. Power Electron. Drive Syst. 2019, 10, 2198. [CrossRef]

34. Yazdanpanah, R.; Mojtaba, M. Axial-Flux Wound-Excitation Eddy-Current Brakes: Analytical Study and Parametric Modeling. IEEE Trans. Magn. 2014, 50, 1-10. [CrossRef]

35. Yazdanpanah, R.; Mirsalim, M. Hybrid Electromagnetic Brakes: Design and Performance Evaluation. IEEE Trans. Energy Convers. 2015, 30, 60-69. [CrossRef]

36. Jin, Y.; Kou, B.; Zhang, L.; Zhang, H.; Zhang, H. Magnetic and Thermal Analysis of a Halbach Permanent Magnet Eddy Current Brake. In Proceedings of the 19th International Conference on Electrical Machines and Systems (ICEMS), Chiba, Japan, 13-16 November 2016.

(C) 2020 by the authors. Licensee MDPI, Basel, Switzerland. This article is an open access article distributed under the terms and conditions of the Creative Commons Attribution (CC BY) license (http://creativecommons.org/licenses/by/4.0/). 